\title{
Erratum to: Relationship between hydrology and vegetation change from Sphagnum lawns to vascular plant Sasa communities
}

\author{
Yoshiyasu Fujimura $\cdot$ Hiroko Fujita $\cdot$ \\ Masayuki Takada $\cdot$ Takashi Inoue
}

Published online: 28 January 2012

(C) International Consortium of Landscape and Ecological Engineering and Springer 2012

\section{Erratum to: Landscape Ecol Eng}

\section{DOI 10.1007/s11355-011-0159-y}

The article has been published online with incorrect author names. As the family names and given names are incorrectly published, the correct information regarding the author group is provided below:

Yoshiyasu Fujimura · Hiroko Fujita · Masayuki Takada · Takashi Inoue

The online version of the original article can be found under doi:10.1007/s11355-011-0159-y.

Y. Fujimura $(\bowtie) \cdot$ H. Fujita

Botanic Garden, Field Science Centre for Northern Biosphere,

Hokkaido University, North 3, West 8, Chuo-ku,

Sapporo 060-0003, Japan

e-mail: fujimura@cen.agr.hokudai.ac.jp

\section{Takada}

Hokkaido Institute of Environmental Science,

North 19, West 12, Kita-ku, Sapporo 060-0819, Japan

T. Inoue

Graduate School of Agriculture, Hokkaido University,

North 9, West 9, Kita-ku, Sapporo 060-8589, Japan 